\title{
Systemic and local zoledronic acid treatment with hydroxyapatite bone graft: A histological and histomorphometric experimental study
}

\author{
NEDIM GÜNES $^{1 *}$, SERKAN DUNDAR $^{2 *}$, ARIF SAYBAK $^{3}$, GÖKHAN ARTAS $^{4}$, IZZET ACIKAN $^{1}$, \\ I. HANIFI OZERCAN ${ }^{4}$, SERHAT ATILGAN ${ }^{5}$ and FERHAN YAMAN ${ }^{1}$ \\ ${ }^{1}$ Department of Oral Maxillofacial Surgery, Faculty of Dentistry, Dicle University, 21280 Diyarbakır; \\ ${ }^{2}$ Department of Periodontology, Faculty of Dentistry, Firat University, 23119 Elazı̆̆; \\ ${ }^{3}$ Private Practice, Periodontists, 01220 Adana; ${ }^{4}$ Department of Medical Pathology, Faculty of Medicine, \\ Firat University, 23119 Elazığ ${ }^{5}$ Private Practice, Oral and Maxillofacial Surgeon, 27260 Gaziantep, Turkey
}

Received December 23, 2015; Accepted February 24, 2016

DOI: 10.3892/etm.2016.3685

\begin{abstract}
In this study, the aim was to compare the relative efficacy of systemic and local zoledronic acid (ZA) on a hydroxyapatite (HA) bone graft in a rat critical-size calvarial bone defect. In total, 84 female rats were divided into four groups: Empty control (EC) group with no treatment applied; HA group, in which only HA bone graft material was used in the calvarium; and HA plus local ZA (HA+LZA) and HA plus systemic ZA (HA+SZA) groups, in which animals received ZA locally or systemically, respectively, with HA bone graft material in the calvarium. A 5-mm standardised critical-size calvarial bone defect was created with a standard trephine drill and the respective treatment was applied. Rats were sacrificed 7, 14 and 28 days later. The numbers of osteoclasts and osteoblasts, and degree of bone formation were evaluated histopathologically and histomorphometrically. Statistically significant differences were detected between the HA, $\mathrm{HA}+\mathrm{LZA}$ and $\mathrm{HA}+\mathrm{SZA}$ groups and the EC group for new bone formation $(\mathrm{P}<0.05)$. Osteoblast numbers in the HA+LZA and $\mathrm{HA}+\mathrm{SZA}$ groups were significantly higher compared with those in the EC and HA groups $(\mathrm{P}<0.05)$. No statistically significant difference was detected between the HA+LZA and HA+SZA groups in new bone formation or osteoblast number $(\mathrm{P}>0.05)$. Bone formation was significantly higher in the HA group than in the EC group $(\mathrm{P}<0.05)$. The numbers of osteoclasts in the $\mathrm{HA}+\mathrm{LZA}$ and HA+SZA groups were significantly higher than
\end{abstract}

Correspondence to: Dr Serkan Dundar, Department of Periodontology, Faculty of Dentistry, Firat University, Campus, 23119 Elazı $\breve{g}$, Turkey

E-mail: dtserkandundar@gmail.com; sdundar@firat.edu.tr

*Contributed equally

Key words: hydroxyapatite bone graft, zoledronic acid, rat calvarium, critical-sized defect those in the groups EC and HA $(\mathrm{P}<0.05)$; however, there was no significant difference between groups HA+LZA and HA+SZA ( $P>0.05)$. Within the limitations of this study, systemic or local administration of ZA enhanced new bone formation with a HA bone graft in a rat critical-size calvarial defect model.

\section{Introduction}

The aim of a bone augmentation procedure in dentistry is the repair of alveolar bone tissue $(1,2)$. In bone tissue repair, the use of autogenous bone grafts remains the gold standard. Autogenous bone grafts have osteoinductive and osteoconductive properties. Additionally, autogenous grafts contain stem cells and growth factors and do not create an immunological reaction. However, the requirement for a second surgical area, the restricted amount of bone grafts, and graft resorption have resulted in a search for alternative graft materials and treatment methods for bone augmentation (3). Human-derived bone grafts are more immunogenic but less osteogenic than autogenous bone grafts, and the resorption rate of allogeneic bone grafts is greater than that of autogenous bone grafts, with an added risk of disease transmission (4). For these reasons, synthetic bone grafts have been developed $(2,4,5)$.

Alloplastic bone grafts should be tissue-compatible, and should not be antigenic or inflammatory. Synthetic bone grafts made of hydroxyapatite (HA) have been demonstrated to stimulate new bone regeneration in experimental animal studies, with high osteogenic potential compared with autologous bone grafts $(2,4,5)$. A HA synthetic bone graft is a type of calcium phosphate ceramic graft. HA synthetic bone grafts, compared with autogenous bone grafts, have been shown to stimulate bone regeneration in experimental animal studies, with excellent stability and bone-regenerative characteristics. Due to their composition and structure, HA bone grafts degrade slowly and are replaced gradually by bone $(4,6,7)$.

Biphosphonates (BPs) are used to prevent and treat increased bone resorption in skeletal diseases. The influence of BPs on 
bone healing and bone-implant connections has been investigated. Throughout bone repair, BPs have been shown to have anti-osteoclastic effects and, thus, a relatively pro-osteoblastic effect (8-11).

BPs have some side effects when used systematically. An initial influenza-like illness, renal failure and osteonecrosis have been documented when BPs have been used systematically (12-14).Zoledronic acid (ZA) is a strong BP in clinical use. Single-dose intraoperative ZA application has shown favourable effects in various models of bone repair and healing (12). In the present study, the aim was to evaluate the effects of locally and systemically administered ZA with HA synthetic bone grafts on new bone generation in a rat critical-size calvarial defect model.

\section{Materials and methods}

Animal care and ethics. The experimental design and study protocol were approved by the Animal Ethics Committee at the University of Dicle (Diyarbakir, Turkey). Rats were obtained from the Sabahattin Payzin Experimental Research of Center Dicle University (Diyarbakır, Turkey). In total, 84 female Sprague Dawley rats, aged 4-6 months were used. Their average body weights were $280-300 \mathrm{~g}$ on the first day of the experiment. The animals were kept in temperature-controlled cages, exposed to a 12/12-h light/dark cycle, and had ad libitum access to food and water.

Experimental protocols and surgical procedure. First, the rats were divided randomly into four groups, as follows: Empty control (EC) group $(n=21)$, no bone graft material or ZA treatment was applied; HA group $(n=21)$, received a HA graft without ZA therapy; HA plus local ZA (HA+LZA) group $(n=21)$, treated locally with ZA; and HA plus systemic ZA (HA+SZA) group $(n=21)$. In the HA+LZA group, each graft was soaked in ZA solution $(1 \mathrm{mg} / \mathrm{ml})$ for $5 \mathrm{~min}$ and unbound $\mathrm{ZA}$ was not rinsed away as described by Toker et al (4). In the HA+SZA group, the rats received $0.1 \mathrm{mg} / \mathrm{kg}$ systemic ZA in sterile injectable saline according to the method of Ayan et al (12), with a HA graft.

General anaesthesia was established using ketamine. All rats were fed with a standard diet during the experimental period. Surgical operations were performed under sterile conditions. Following general anaesthesia, prior to surgery, the skull skin was shaved. A skin incision on the skull was made over the linea media. An incision allowing reflection of a full-thickness flap in the anterior-posterior direction was made in the scalp in the sagittal plane. A periosteal elevator was used to lift the flap and periosteum to access the skull bone. A 5-mm-diameter defect was made in the right side of the calvarium with a standard trephine drill used in a low-speed handpiece under continuous irrigation with sterile saline. During this process, extreme care was taken not to damage the dura mater. The rats in each group were treated as indicated above. All surgical procedures were performed by the same surgeon (SD).

The skull skin was sutured with $4 / 0$ polyglactin resorbable sutures. Cephalosporin antibiotic $(50 \mathrm{mg} / \mathrm{kg})$ and an analgesic (tramadol hydrochloride, $0.1 \mathrm{mg} / \mathrm{kg}$ ) were injected intramuscularly in all animals after the surgery.

After 7, 14 and 28 days, rats were sacrificed (7 rats from each group at each time point) with an anaesthetic overdose (ketamine at a dose 2-3-fold higher than the anaesthetic dosage). After this, a surgical drill attached to an electrical hand motor piece was used to harvest the calvarial bone. The calvarial bone specimens were then separated from muscles and soft tissues (15).

Histological and histomorphological analysis. The original defect area and the surrounding tissues were used for histological analysis. The specimens were fixed in $10 \%$ formaldehyde for $72 \mathrm{~h}$ and demineralised in $10 \%$ formic acid; after this, they were dehydrated, embedded in paraffin wax, and sectioned for haematoxylin and eosin staining for light microscopic analysis. Sections $6-\mu \mathrm{m}$ in thickness, corresponding to the bone defect area, were evaluated by light microscopy. Osteoblast numbers were scored in the total defect area, as follows: No osteoblast cells, 0; low-density osteoblasts, 1; and dense osteoblasts, 2. Osteoclast numbers were scored as follows: No osteoclasts, 0; low-density osteoclasts, 1 ; and dense osteoclasts, 2 . Bone formation was scored as follows: No bone formation, 0 ; mild visible bone formation, 1 ; moderate visible bone formation, 2 ; and dense visible bone formation, 3. Images of all histological specimens were captured with a digital camera attached to a light microscope (Olympus Bx51; Olympus Corporation, Tokyo, Japan) with original magnification and saved on a computer $(4,5)$. Imaging software (Olympus DP71; Olympus Corporation) was used for histomorphometric analysis.

Statistical analysis. For statistical analysis, SPSS software was used (version 22; IBM SPSS, Armonk, NY, USA). Following the healing period, mean values and standard deviations were calculated. The differences between groups were tested with one-way analysis of variance for parameters that showed a normal distribution. For identification of the specific groups with significant differences, Tukey's honest significant difference test was used. $\mathrm{P}<0.05$ was considered to indicate a statistically significant difference.

\section{Results}

Healing and bone formation. In the EC group, healing was characterised by thin fibrous connective tissue filling the defects, due to no bone graft material or treatment being applied. In addition, no regenerative bone formation was detected. At 28 days, the amount of new bone formation in all study groups had increased in comparison with that in the EC group $(\mathrm{P}<0.05)$. Semi-quantitative analyses demonstrated that there was new bone formation in groups HA, HA+LZA, and $\mathrm{HA}+\mathrm{SZA}$ at 28 days. The two routes of ZA administration resulted in significantly higher new bone formation than in group HA $(\mathrm{P}<0.05)$. However, no significant difference was observed between the two routes of $\mathrm{ZA}$ administration at 28 days $(\mathrm{P}>0.05)$. On days 7 and 14 , no new bone formation was detected in any group $(\mathrm{P}>0.05)$. Overall, the mean new bone area in the EC group was significantly lower than that in groups $\mathrm{HA}, \mathrm{HA}+\mathrm{LZA}$, and $\mathrm{HA}+\mathrm{SZA}(\mathrm{P}<0.05)$. Additionally the results demonstrated no significant difference in new bone area between groups $\mathrm{HA}+\mathrm{LZA}$ and $\mathrm{HA}+\mathrm{SZA}(\mathrm{P}<0.05$; Figs. 1 and 2).

Osteoclast numbers. At day 28, osteoclast numbers in groups $\mathrm{HA}+\mathrm{LZA}$ and $\mathrm{HA}+\mathrm{SZA}$ were significantly higher than those in the EC and HA groups $(\mathrm{P}<0.05)$. Osteoclast numbers in groups 


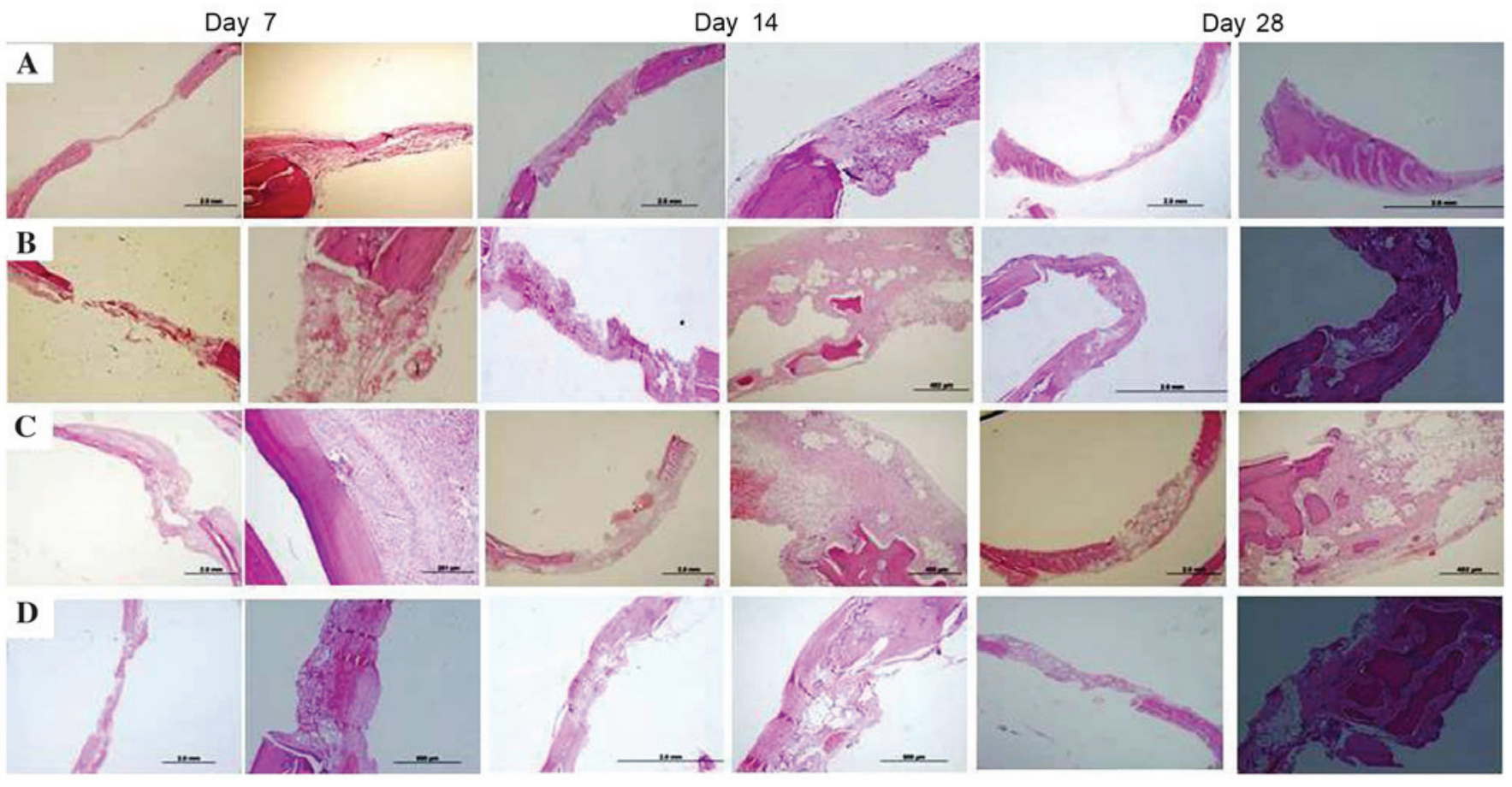

Figure 1. Histopathological findings of the (A) EC group, (B) HA group, (C) HA+LZA group and (D) HA+SZA group on days 7, 14 and 28. Haematoxylin and eosin staining; magnification $\mathrm{x} 2$ and $\mathrm{x} 4$ for left and right images at each time point, respectively. In the EC group, healing was characterised by thin fibrous connective tissue filling the defects, and no regenerative bone formation was detected at any time point. By day 28 , new bone formation was visible in all three treatment groups. ZA administration, either systemically or locally, resulted in increased bone formation and greater numbers of osteoclasts and osteoblasts in comparison with those in the HA group. EC, empty control; HA, hydroxyapatit LZA, local zoledronic acid; SZA, systemic zoledronic acid.

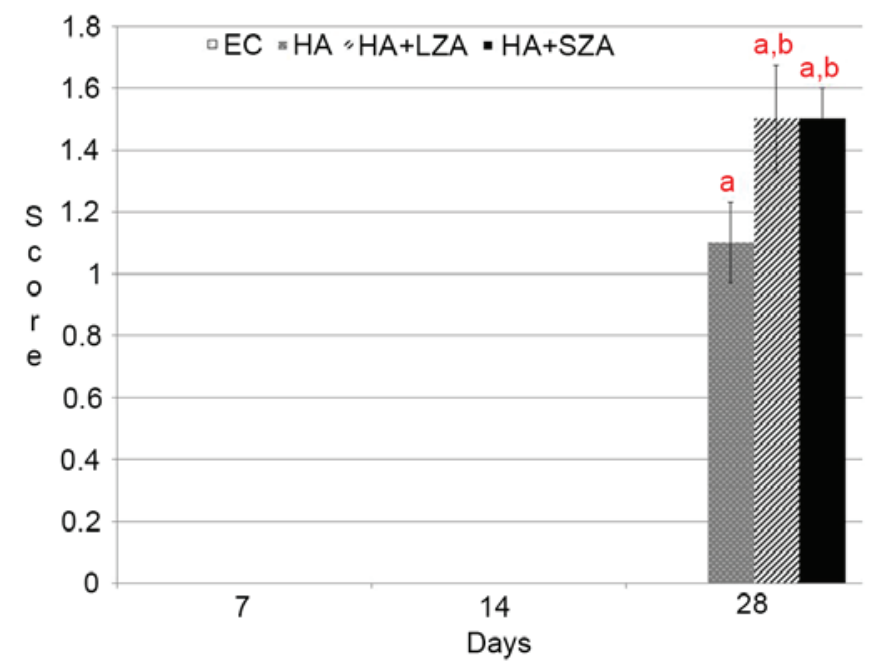

Figure 2. Bone formation of the groups on days 7, 14 and 28. Bone formation was scored as follows: No bone formation, 0 ; mild visible bone formation, 1 ; moderate visible bone formation, 2 ; dense visible bone formation, 3. Data are presented as mean \pm standard deviation ( $\mathrm{n}=7$ at each time point). ${ }^{a} \mathrm{P}<0.05$ vs. the EC group; ${ }^{\mathrm{P}} \mathrm{P}<0.05$ vs. the HA group. EC, empty control; HA, hydroxyapatit LZA, local zoledronic acid; SZA, systemic local zoledronic acid.

HA+LZA and HA+SZA were not significantly different from each other $(\mathrm{P}>0.05)$; however, both were significantly higher compared with the osteoclast number in group HA $(\mathrm{P}<0.05)$. At day 14 , osteoclast numbers were significantly higher in groups $\mathrm{HA}, \mathrm{HA}+\mathrm{LZA}$ and $\mathrm{HA}+\mathrm{SZA}$ than in group $\mathrm{EC}(\mathrm{P}<0.05)$. No significant difference was observed among groups HA,

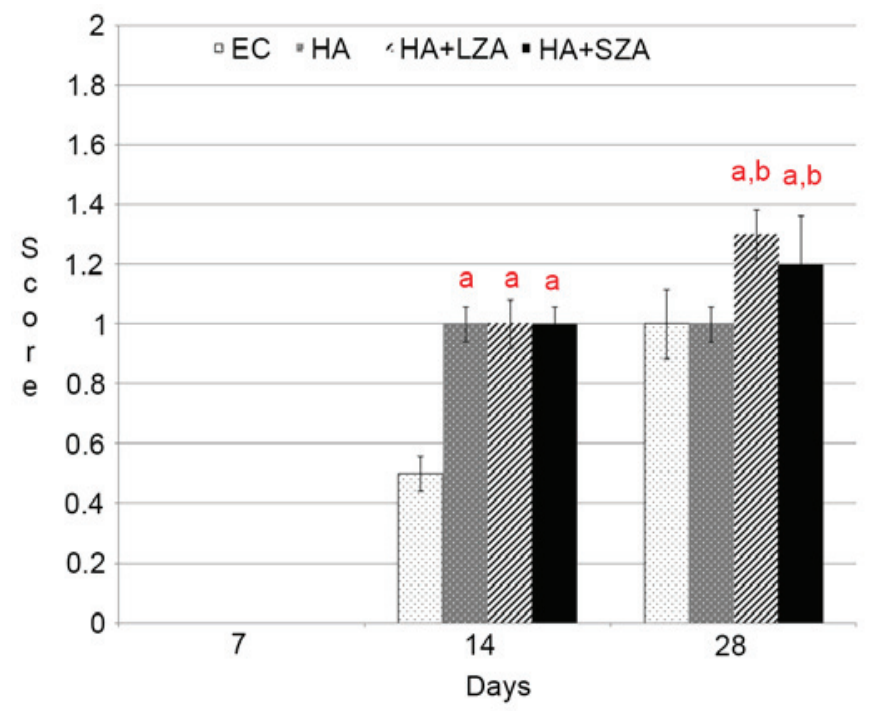

Figure 3. Osteoclast number of the groups on days 7, 14 and 28. Osteoclast numbers were scored as follows: No osteoclasts, 0 ; low-density osteoclasts, 1 ; dense osteoclasts, 2 . Data are presented as mean \pm standard deviation $(n=7$ at each time point). ${ }^{a} \mathrm{P}<0.05$ vs. the $\mathrm{EC}$ group; ${ }^{\mathrm{b}} \mathrm{P}<0.05$ vs. the HA group. $\mathrm{EC}$, empty control; HA, hydroxyapatit LZA, local zoledronic acid; SZA, systemic local zoledronic acid.

$\mathrm{HA}+\mathrm{LZA}$ and $\mathrm{HA}+\mathrm{SZA}$ with respect to osteoclast numbers ( $\mathrm{P}>0.05$; Figs. 1 and 3 ).

Osteoblast numbers. At day 28, the numbers of osteoblasts in groups HA, HA+LZA, and HA+SZA were significantly 


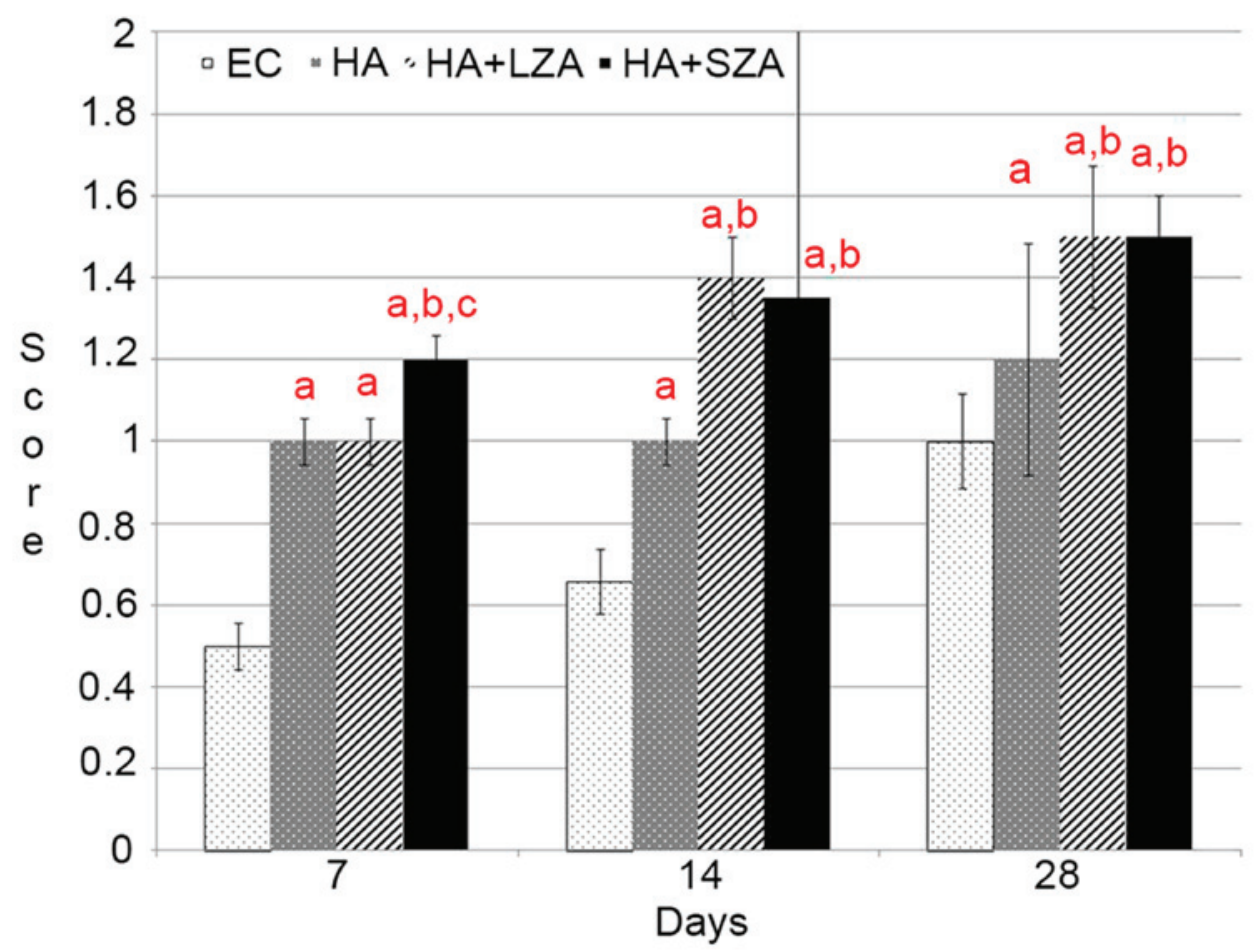

Figure 4. Osteoblast number of the groups on days 7, 14 and 28. Osteoblast numbers were scored as follows: No osteoblasts, 0 ; low-density osteoblasts, 1; and dense osteoblasts, 2. Data are presented as mean \pm standard deviation ( $\mathrm{n}=7$ at each time point). ${ }^{\mathrm{a}} \mathrm{P}<0.05$ vs. the EC group; ${ }^{\mathrm{b}} \mathrm{P}<0.05$ vs. the $\mathrm{HA}$ group; ${ }^{\mathrm{P}} \mathrm{P}<0.05$ vs. the HA+LZA group. EC, empty control; HA, hydroxyapatit LZA, local zoledronic acid; SZA, systemic local zoledronic acid.

higher than in the EC group $(\mathrm{P}<0.05)$. There was no significant difference in osteoblast number between groups HA+LZA and $\mathrm{HA}+\mathrm{SZA}$ at day $28(\mathrm{P}>0.05)$, although osteoblast cell numbers in groups $\mathrm{HA}+\mathrm{LZA}$ and $\mathrm{HA}+\mathrm{SZA}$ were significantly higher than in the HA group $(\mathrm{P}<0.05)$. At day 14 , osteoblast numbers in groups $\mathrm{HA}+\mathrm{LZA}$ and $\mathrm{HA}+\mathrm{SZA}$ were significantly higher than in the EC and HA groups $(\mathrm{P}<0.05)$. Osteoblast numbers were also significantly higher in the HA group than in the EC group $(\mathrm{P}<0.05)$. Newly regenerated bone formation was not detected in the EC group $(\mathrm{P}>0.05)$. No significant difference was detected in new bone formation between groups HA+LZA and HA+SZA ( $\mathrm{P}>0.05$; Figs. 1 and 4 ).

\section{Discussion}

Rat calvarial defects are considered a preferred experimental model for bone regeneration in experimental studies, as poor vascular supply and membranous structures inhibit natural healing $(4,5)$. In the present study, a 5-mm critical-size defect model in rat calvaria was used. The reason for using a defect of this size is that in bone defects greater than this, healing with scarring occurs as opposed to bone regeneration, resulting in defect cavity formation. This was confirmed in the present study; no new bone formation was detected in the control defects $(4,5)$.

BP pretreatment can be useful to prevent bone graft resorption. Additionally, bone cell culture studies have indicated that BPs can increase bone formation indicators at very low concentrations $(5,12)$. Due to their direct action on osteoclasts, it is evident that BPs may affect the bone formation process. Osteoclast cell function may be changed by the production of an osteoclastic inhibitory factor secreted by osteoblasts following BP administration. During the bone remodelling process, osteoblastic cells control the activity of osteoclastic cells. BPs increase the proliferation and maturation of osteoblastic cells and reduce apoptosis $(4,5,12)$. This supports the hypothesis that BPs may have an anabolic effect on bone tissue cells and thus increase bone tissue formation. As such, the target cells of BPs may include members of the osteoblastic cell family $(12,16)$. It has been shown that BPs can increase the proliferation of osteoblasts and the synthesis of collagen and osteocalcin by bone cells at the cellular level $(4,5)$. In the present study, histological analysis indicated that the newly formed bone area was larger in all study groups at the end of the study (at 28 days) compared with that in the EC group. Systemic and topical application of ZA resulted in significantly more bone formation than was observed in group HA, with no significant difference between the two application routes of ZA administration at day 28. New bone formation was not observed in the EC group. In terms of new bone formation, no significant difference was observed between groups HA+LZA and HA+SZA. This result confirms the results of earlier studies regarding bone augmentation with local and systemic ZA application and the association between bone tissue cells and BPs $(4,5)$.

In the present study, it was hypothesized that ZA would activate osteoblastic cells and increase osteogenesis. Mixing the grafts with BP solution prior to application on the bone defects seemed to be a reasonable approach. Treating the bone with local BP may facilitate bone tissue healing without systemic effects. In earlier studies, it was reported that local application of BP solution on an allograft increased osteogenesis (4-6). 
$\mathrm{ZA}$ is a strong BP that is used clinically. A single dose of ZA administered intraoperatively has shown favourable effects in various models of bone repair and healing (12). Systemic BP application has been used widely in the treatment of various systemic skeletal metabolic bone diseases, such as Paget's disease, hypercalcaemia of malignancy and post-menopausal osteoporosis $(12,17,18)$. It is clear that BPs in bone tissues inhibit bone turnover and, thus, bone tissue loss $(12,19)$. The present study confirmed thi ZA treatment of the bone graft, locally and systemically, increased osteogenesis of the graft material and enabled bone formation, compared with that in the control and graft-only groups. In this study, at day 28, favourable effects of local and systemic BP were observed in groups HA+LZA and $\mathrm{HA}+\mathrm{SZA}$ in terms of newly regenerated bone formation, which is consistent with previous reports $(4,5,10-12,20,21)$. However, in terms of new bone formation and osteoblast and osteoclast numbers, no significant difference was observed between groups HA+LZA and HA+SZA. As the amount of new bone formation in the HA+LZA and HA+SZA groups was similar, a statistically significant difference was not detected between the two groups for osteoblast and osteoclast numbers. The bone formation results can be explained by the osteoblast and osteoclast numbers observed in the two groups.

The type of application and dose of BP are key factors in the understanding of bone tissue and BP interaction. Previous studies have indicated that BPs cause a biphasic effect, stimulating cellular reproduction and the formation of bone cell tissues at low concentrations and restricting these processes at higher concentrations $(4,22-25)$. In a study using an experimental periodontitis model, the preventative effects of BPs were investigated in alveolar bone tissue destruction at two doses. It was demonstrated that treatment with BPs in the experimental group, given either as a prophylactic or therapeutic medication, significantly inhibited inflammatory tissue destruction and alveolar bone resorption in comparison with the saline-treated control group (21). Myoung et al (26) investigated the effects of a BP at a dose of $0.01 \mathrm{mg} / \mathrm{kg} / \mathrm{day}$ on the expression of bone tissue regeneration-related genes following autogenous bone graft application in an experimental rat model. They demonstrated that the BP inhibited osteoclastic function and triggered osteoblasts to secrete an inhibitor of osteoclast-related resorption. In another animal model study, BPs were administered systemically at a dose of $0.25 \mathrm{mg} /$ day for 8 weeks, and it was shown that alendronate stimulated bone regeneration in autogenous bone grafts (20). In the present study, to compare the systemic effects of ZA with those of local ZA pre-treatment of the bone graft, systematic ZA was used at a dose of $0.1 \mathrm{mg} / \mathrm{kg}$ according to Ayan et al (12) and local ZA at a concentration of $1 \mathrm{mg} / \mathrm{ml}$ according to Toker et al (4). The results suggest that favourable effects occurred in the HA+LZA and HA+SZA groups regarding new bone formation, compared with the graft-only group, which is consistent with the findings of Ayan et al (12) and Toker et al (4).

BPs primarily reach revascularised sections of bone tissue when used systemically, but not the unvascularised graft (4). However, long-term BP use has been associated with osteonecrosis of the jaw $(13,14)$. Local BP treatment of bone tissues provides protection against bone resorption, without any broader skeletal effects (4). Additionally, in local BP pretreatment, the majority of the BP adsorbs to the bone surface of cancellous bone while a small volume stays free in solution between the trabeculae $(4,10)$. Furthermore, topical treatment of an allograft with a BP has been shown to inhibit bone graft resorption (4). Another experimental study using a synthetic bone graft suggested that a single dose of local BP pretreatment combined with the bone graft improved bone tissue regeneration in the rat mandible (27). A study investigating the influence of systemic BPs on synthetic bone graft osteogenesis in a posterolateral spinal fusion porcine model showed that BPs at a dose of $10 \mathrm{mg} /$ day did not inhibit bone formation within the synthetic bone graft and did not demonstrate differences in trabecular bone volume between treatment and control groups (28). In the present study, favourable effects were observed with topical BP pretreatment at $1 \mathrm{mg} / \mathrm{ml}$ concentration in the HA+LZA group, as previously reported $(11,27)$.

In the present study, ZA was administered systemically as a single dose of $0.1 \mathrm{mg} / \mathrm{kg}(12,29-32)$. According to previous reports, the plasma concentration of BPs declines progressively over 28 days $(12,32)$. A repeat dose of ZA could be administered 28 days after the initial single dose, if required. The administration of an intra-operative single dose of $0.1 \mathrm{mg} / \mathrm{kg}$ ZA was considered to be sufficient for the bone healing period in the present study, according to Ayan et al (12). Thus, for the comparison of local and systemic single BP administration in the present study, a 28-day experimental period was selected because of the use of a single local application of ZA with the HA graft.

In conclusion, the present study demonstrated that systemic and local BP treatment can increase bone formation in HA grafts in a rat critical-size defect model, compared with that in rats treated with graft alone. Considering the risks associated with systemic BP therapy, we suggest that further studies focusing on local and systemic applications of ZA at different doses and/or concentrations and different graft materials may be effective in identifying methods for the enhancement of healing using bone graft materials.

\section{Acknowledgements}

The authors thank Dr Selcuk Ilhan (Department of Pharmacology, Faculty of Medicine, Firat University) for helpful advice with the statistical analysis.

\section{References}

1. Buser D, Brägger U, Lang NP and Nyman S: Regeneration and enlargement of jaw bone using guided tissue regeneration. Clin Oral Implants Res 1: 22-32, 1990.

2. Ezirganli S, Polat S, Baris E, Tatar I and Celik HH: Comparative investigation of the effects of different materials used with a titanium barrier on new bone formation. Clin Oral Implants Res 24: 312-319, 2013.

3. Alam S, Ueki K, Nakagawa K, Marukawa K, Hashiba Y, Yamamoto E, Sakulsak S and Iseki N: Statin-induced bone morphogenetic protein (BMP) 2 expression during bone regeneration: An immunohistochemical study. Oral Surg Oral Med Oral Pathol Oral Radiol Endod 107: 22-29, 2009.

4. Toker H, Ozdemir H, Ozer H and Eren K: A comparative evaluation of the systemic and local alendronate treatment in synthetic bone graft: A histologic and histomorphometric study in a rat calvarial defect model. Oral Surg Oral Med Oral Pathol Oral Radiol 114 (5 Suppl): S146-S152, 2012.

5. Toker H, Ozdemir H, Ozer H and Eren K: Alendronate enhances osseous healing in a rat calvarial defect model. Arch Oral Biol 57: 1545-1550, 2012. 
6. Fellah BH, Gauthier O, Weiss P, Chappard D and Layrolle P: Osteogenicity of biphasic calcium phosphate ceramics and bone autograft in a goat model. Biomaterials 29: 1177-1788, 2008.

7. Mah J, Hung J, Wang J and Salih E: The efficacy of various alloplastic bone grafts on the healing of rat calvarial defects. Eur J Orthod 26: 475-482, 2004.

8. Doggrell SA: Clinical efficacy and safety of zoledronic acid in prostate and breast cancer. Expert Rev Anticancer Ther 9: 1211-1218, 2009.

9. Lipton A: The safety of zoledronic acid. Expert Opin Drug Saf 6: 305-313, 2007.

10. Jakobsen T, Baas J, Kold S, Bechtold JE, Elmengaard B and Søballe K: Local bisphosphonate treatment increases fixation of hydroxyapatite-coated implants inserted with bone compaction. J Orthop Res 27: 189-194, 2009.

11. Jakobsen T, Baas J, Bechtold JE, Elmengaard B and Søballe K: Soaking morselized allograft in bisphosphonate can impair implant fixation. Clin Orthop Relat Res 463: 195-201, 2007.

12. Ayan M, Dolanmaz D, Mihmanli A, Ayan A and Kürkcü M: The effect of systemically administrated zoledronic acid on the osseointegration of dental implants. Oral Dis 18: 802-808, 2012.

13. Ruggiero SL: Bisphosphonate-related osteonecrosis of the jaw (BRONJ): Initial discovery and subsequent development. J Oral Maxillofac Surg 67 (5 Suppl): S13-S18, 2009.

14. Ruggiero SL, Mehrotra B, Rosenberg TJ and Engroff SL: Osteonecrosis of the jaws associated with the use of bisphosphonates: A review of 63 cases. J Oral Maxillofac Surg 62: 527-534, 2004

15. Yaman F, Atilgan S, Günes N, Agacayak S, Günay A, Ucan MC, Bakir S, Erol B, Kose I and Atalay Y: Phosphodiesterase-5 inhibitors may facilitate bone defect recovery. Eur Rev Med Pharmacol Sci 15: 1301-1305, 2011.

16. Ozdemir H, Ezirganli S, Isa Kara M, Mihmanli A and Baris E: Effects of platelet rich fibrin alone used with rigid titanium barrier. Arch Oral Biol 58: 537-544, 2013.

17. Walsh JP, Ward LC, Stewart GO, Will RK, Criddle RA, Prince RL, Stuckey BG, Dhaliwal SS, Bhagat CI, Retallack RW, et al: A randomized clinical trial comparing oral alendronate and intravenous pamidronate for the treatment of Paget's disease of bone. Bone 34: 747-754, 2004

18. Wellington K and Goa KL: Zoledronic acid: A review of its use in the management of bone metastases and hypercalcaemia of malignancy. Drugs 63: 417-437, 2003.

19. Rodan GA and Fleisch HA: Bisphosphonates: Mechanisms of action. J Clin Invest 97: 2692-2696, 1996.

20. Altundal $\mathrm{H}$ and Gursoy B: The influence of alendronate on bone formation after autogenous free bone grafting in rats. Oral Surg Oral Med Oral Pathol Oral Radiol Endod 99: 285-291, 2005.
21. Menezes AM, Rocha FA, Chaves HV, Carvalho CB, Ribeiro RA and Brito GA: Effect of sodium alendronate on alveolar bone resorption in experimental periodontitis in rats. J Periodontol 76: 1901-1909, 2005

22. Coxon FP, Thompson K and Rogers MJ: Recent advances in understanding the mechanism of action of bisphosphonates. Curr Opin Pharmacol 6: 307-312, 2006.

23. von Knoch F, Jaquiery C, Kowalsky M, Schaeren S, Alabre C, Martin I, Rubash HE and Shanbhag AS: Effects of bisphosphonates on proliferation and osteoblast differentiation of human bone marrow stromal cells. Biomaterials 26: 6941-6949, 2005.

24. Kaynak D, Meffert R, Günhan M, Günhan O and Ozkaya O: A histopathological investigation on the effects of the bisphosphonate alendronate on resorptive phase following mucoperiosteal flap surgery in the mandible of rats. J Periodontol 71: 790-796, 2000.

25. Idris AI, Rojas J, Greig IR, Van't Hof RJ and Ralston SH: Aminobisphosphonates cause osteoblast apoptosis and inhibit bone nodule formation in vitro. Calcif Tissue Int 82: 191-201, 2008.

26. Myoung H, Park JY and Choung PH: Effects of a bisphosphonate on the expression of bone specific genes after autogenous free bone grafting in rats. J Periodontal Res 36: 244-251, 2001.

27. Xue QY, Ji Q, Li HS, Zou XN, Egund N, Lind M, Christensen FB and Bünger $C$ : Alendronate treatment does not inhibit bone formation within biphasic calcium phosphate ceramics in posterolateral spinal fusion: An experimental study in porcine model. Chin Med J (Engl) 122: 2770-2774, 2009.

28. Srisubut S, Teerakapong A, Vattraphodes $T$ and Taweechaisupapong S: Effect of local delivery of alendronate on bone formation in bioactive glass grafting in rats. Oral Surg Oral Med Oral Pathol Oral Radiol Endod 104: e11-e16, 2007.

29. Pampu AA, Dolanmaz D, Tüz HH and Karabacakoglu A: Experimental evaluation of the effects of zoledronic acid on regenerate bone formation and osteoporosis in mandibular distraction osteogenesis. J Oral Maxillofac Surg 64: 1232-1236, 2006.

30. Yildiz A, Esen E, Kürkcü M, Damlar I, Dağlioğlu K and Akova T: Effect of zoledronic acid on osseointegration of titanium implants: An experimental study in an ovariectomized rabbit model. J Oral Maxillofac Surg 68: 515-523, 2010.

31. Tatli U, Ustün Y, Kürkcü M, Erdoğan O, Gürbüz CC, Ozgür H and Polat S: Effects of zoledronic acid on healing of mandibular fractures: An experimental study in rabbits. J Oral Maxillofac Surg 69: 1726-1735, 2011.

32. Chen T, Berenson J, Vescio R, Swift R, Gilchick A, Goodin S, LoRusso P, Ma P, Ravera C, Deckert F, et al: Pharmacokinetics and pharmacodynamics of zoledronic acid in cancer patients with bone metastases. J Clin Pharmacol 42: 1228-1236, 2002. 